\title{
DESPEDIDA DO PROF. GOFFREDO DA SILVA TELLES \\ DA PRESIDÊNCIA DA CPG - ATA DA REUNIÃO \\ OCORRIDA EM 10 DE DEZEMBRO DE 1973
}

"Finalmente, passando ao último item da Ordem do dia, o professor Goffredo Telles Júnior se pronunciou nos seguintes temas:

'Precisamente na data de hoje, faz vinte e um meses que sou coordenador da Comissão de Pós-Graduação.

Durante tal período esta Comissão realizou dezenove sessões. Não foi possível efetuar as duas sessões planejadas para julho e agosto de 1972, porque a maior parte dos membros da Comissão se achava ausente de São Paulo. Pela mesma razão, não se realizaram as três sessões que estavam planejadas para junho e julho de 1973 .

Das vinte e quatro sessões por mim convocadas, dezenove se realizaram efetivamente, com a presença de um número suficiente de professores para deliberar, como atestam as oitenta e uma páginas de atas do nosso Livro de Atas. Nesse total de páginas, não estão inclusas, como é óbvio, as páginas da ata da presente sessão.

Desejo relembrar, sinteticamente os seguintes fatos:

Em 28 de outubro de 1971, a egrégia Congregação, não querendo atender a meu expresso pedido de não me incluir na Comissão de Pós-Graduação, constrangeu-me amavelmente, com uma salva de palmas, a participar dela. O Presidente e Coordenador da Comissão era o Professor Philomeno Joaquim da Costa.

Com o rompimento das relações desse professor com o Diretor da Faculdade Professor José Pinto Antunes, exonerei-me da Comissão.

Na sessão de 2 de março de 1972, do Conselho Interdepartamental, apresentei, a título de colaboração, um rol de normas práticas para o funcionamento do Curso de Pós-Graduação. E, na sessão de 9 de março, do mesmo Conselho, ofereci um projeto de Portaria, contendo as mencionadas normas. Este projeto foi aprovado pelo CID.

A convite do Diretor da Faculdade, participei da sessão da Comissão de Pós-Graduação, que se realizou em 10 de março. Nesta sessão, o professor Cesarino Júnior, por telefone, comunicou que não queria mais participar da Comissão, e sugeriu meu nome, para substituí-lo. O senhor Diretor me pediu que aceitasse voltar para a Comissão. Embora sabendo que eu teria que interromper os meus trabalhos, em minha nova linha de pesquisas, sobre a autonomia da vontade e sobre o fundamento biológico da ordenação jurídica, resolvi aquiescer. No dia, meus colegas me elegeram Coordenador da Comissão de Pós-Graduação. 
Onze dias depois, a 21 do mesmo mês de março, apresentei a esta Comissão a relação das falhas principais de nosso curso. Tal relação consta da ata da sessão realizada nesse dia, e por ela se verifica a massa imensa de trabalho que preciso realizar imediatamente, para a legalização do curso de Pós-Graduação de nossa Faculdade.

Não é preciso que eu faça, agora, o relatório de como esse trabalho se realizou. Muitas foram as testemunhas diárias de nosso esforço.

Para que se tenha uma ideia da situação em que nos encontramos, quando assumi a Coordenadoria, no início do segundo período letivo do Curso (primeiro semestre de 1972), basta dizer que ainda não se tinha nem sequer o esboço de uma secretaria. Sem arquivos nem fichário, sem registros nem livro de atas, sem uma só mesa ou uma só gaveta, não se sabia da situação de nenhum dos candidatos matriculados. De nenhum candidato, em verdade, se conheciam os níveis, a média alcançada, as unidades de créditos, a Área de Concentração, a Área Complementar. Nem sequer se podia dizer quais eram os candidatos matriculados, porque, sem o cálculo das médias, impossível saber quais estavam "desligados" e quais os que tinham condições de manter suas matrículas.

Houve um momento negro de desesperança em que eu e meus devotados auxiliares tivemos a impressão de que era preciso recomeçar o curso, desde marco zero, e pedir a todos, professores e candidatos, que consentissem no simples cancelamento da balbúrdia, em que se redundaram, afinal, os trabalhos letivos do primeiro período.

A alta compreensão de meus extraordinários colegas de Congregação foi o que criou as condições necessárias para que vencêssemos a crise daquele momento. A egrégia Congregação me concedeu tempo, o tempo de que eu precisava para arrumar a casa, e expressamente concordou com o adiamento da reabertura dos cursos.

Paulatinamente, fomos abrindo o caminho e pondo ordem em nossa PósGraduação.

Aos 27 de abril de 1972, a Congregação, por vinte e dois votos num total de vinte e seis votando, me elegeu seu Representante, junto ao Conselho Universitário.

No Conselho Universitário, fui eleito para o Conselho de Ensino, Pesquisa e Extensão de Serviços à Comunidade, conhecido pela sigla CEPE, e para a Comissão de Legislação e Recursos.

Em sessão de 23 de maio de 1972, o CEPE me elegeu para a Câmara de Pós-Graduação.

Quero revelar que li e possuo em meu poder cópia de todas as atas e decisões da Câmara a que passei a pertencer. Li e possuo em meu poder todas as atas e decisões do órgão que antecedeu essa Câmara, a CCP, a Coordenação Central de Pós-Graduação. Li e possuo em meu poder cópia de todos os pareceres e votos sobre Pós-Graduação, emitidos pelo Conselho Federal de Educação. Enfronhei-me em toda 
legislação sobre cursos de Mestrado e Doutorado. Estudei a organização desses cursos em muitas Universidades estrangeiras. Organizei, para meu governo na Faculdade de Direito, e para fundamentação de meus pareceres e votos na Câmara de Pós-Graduação, um grande "dossier", que contem, ordenadas rigorosamente de acordo com seus assuntos, todas as normas vigentes sobre Pós-Graduação.

Aos 5 de outubro de 1972, a Congregação da Faculdade de Direito, em obediência ao disposto no Art. 154 do Regimento Geral da USP, elegeu os membros de sua Comissão de Pós-Graduação, mantendo os que já a compunham. Foram eleitos os professores Goffredo da Silva Telles Júnior, Vicente Marotta Rangel, Oscar Barreto Filho, Manoel Gonçalves Ferreira Filho e Moacyr Lobo da Costa.

Devo dizer que o "imenso trabalho", a que me referi no início de meu breve relatório, foi integralmente realizado. Dediquei-lhe, com amor, durante vinte e um meses, os dois períodos diários de minha atividade; eu deveria dizer, para ser mais exato, os três ${ }^{1}$ períodos de minha jornada, porque o meu dia de trabalho, em regra, principia com um período que vai das quatro da madrugada às sete horas da manhã. Dediqueilhe, também, muitos de meus sábados e domingos. Contei, para executá-lo, com a orientação esclarecida e indefectível de Vossas Excelências. Tive a sorte de encontrar, para a organização da Secretaria da CPG, a competência, a perseverança e a fidelidade, da professora Henny Goulart. E, para felicidade minha, pude construir uma secretaria eficiente, com funcionários que souberam cumprir seu dever: Luiz Pereira Pagliarini, André Raposo Brito e Hilda Alvez de Alvarenga.

Tenho a satisfação de poder declarar que nosso curso de Pós-Graduação, no dia de hoje, está estruturando e se desenvolve em rigorosa conformidade com as normas do Conselho Federal de Educação, da Reitoria da USP e da Câmara de PósGraduação. Todos os serviços da Secretaria da CPG foram racionalizados e se acham em pleno funcionamento. Instruções e formulários, elaborados com prudência e esmero, hoje facilitam os trabalhos. Arquivos e fichários estão completos e eficientes, rigorosamente atualizados, aptos a fornecer, em poucos segundos, as informações que forem necessárias, sobre todos os candidatos do curso. Cada candidato tem seu "prontuário" e sua ficha. Cada Área de estudo tem sua pasta, contendo cópia atualizada de seu processo de credenciamento. De cada disciplina, há cópia dos programas devidamente aprovados e das correspondentes bibliografias. De cada professor, consta biografia e o respectivo processo de credenciamento.

A situação problemática dos antigos alunos de nosso velho Curso de Especialização foi integralmente regularizada, na Câmara de Pós-Graduação. Número

\footnotetext{
1 Grifo do original 
muito grande desses alunos já obteve a computação das unidades de crédito a que passaram a ter direito.

Todo o nosso expediente está em dia. Sobre a minha mesa, não há um único papel a despachar.

Agora, é chegado o momento de informar a meus nobre e queridos colegas que tomei a resolução, definitiva e irrevogável, de me exonerar, a partir do dia de hoje, do cargo de Coordenador de nossa Comissão de Pós-Graduação e de minhas funções de membro de mesma comissão.

Deixo para meu sucessor, como problemas a resolver, apenas as questões novas, as inevitáveis dificuldades que, necessariamente, surgem, com simples e natural desenrolar do curso. Mas é possível que meu sucessor encontre, se assim o quiser, muitas sugestões para a solução desses problemas, nas soluções já dadas a problemas passados.

Quanto a mim, o que só almejo é voltar a ser o que essencialmente sou.

Dos cargos administrativos, nesta minha Faculdade, nada quero, nada pleiteio, a nenhum me candidato. Aliás, posso afirmar que essa tem sido sempre minha atitude. Se meu nome apareceu, vez ou outra, como o de candidato a isto ou aquilo, as circunstâncias é que o colocaram nessa situação. E quando escolhido para qualquer trabalho, muito mais pensei no encargo do que no cargo: o que só procurei foi executar minha tarefa.

Meu ideal não é, em absoluto, ser Coordenador da Pós-Graduação ou Diretor da Faculdade. Meu ideal é ser um bom professor de meus alunos; é respeitá-los e amá-los; é ser respeitado e amado por eles. E é meu ideal, também, ter a possibilidade de meditar na solidão e de escrever em silêncio.

Cumprirei, se isto não se transformar em tormento, o honroso mandato que a egrégia Congregação me conferiu: o de ser seu Representante no Conselho Universitário. Mas tal mandato termina no dia 26 de abril do próximo ano. Depois dessa data, nada mais desejarei, dentro do campo de minha profissão, do que dedicar minha vida à docência e à pesquisa.

Aceitem, meus ilustres colegas, queridos companheiros de trabalho, as expressões de meus mais sinceros agradecimentos.'

O Senhor Diretor declarou que. traduzindo a emoção de todos, ao ouvirem a comunicação, apresentava ao professor Goffredo da Silva Telles Júnior os agradecimentos da Comissão pelo trabalho contínuo e dedicado que desenvolvera como coordenador da CPG.

O professor Oscar Barreto Filho declarou que todos respeitavam a decisão do professor Goffredo da Silva Telles Júnior, mas que fazia um apelo para que permanecesse na Comissão, já que não desejava permanecer como coordenador. 
Todos os presentes associaram-se ao apelo dirigido ao professor Goffredo da Silva Telles Júnior. Este agradeceu mas disse que sua decisão era firme.

O professor Oscar Barreto Filho sugeriu fosse o professor Vicente Marotta Rangel escolhido para assumir a coordenação da CPG, até que a Congregação eleja a nova comissão, para não ficar acéfala.

O professor Vicente Marotta Rangel declarou que preferia que o professor Oscar Barreto Filho assumisse essas funções. Diante da recusa do professor Oscar Barreto Filho, o professor Vicente Marotta Rangel concordou em aceitar o encargo.

O professor Manoel Gonçalves Ferreira Filho encerrou a sessão às 12:30 horas." 